\title{
Effect of Depression and Antidepressants on Sexual Dysfunction in Men with Diabetes: A National Population-Based Cohort Study
}

This article was published in the following Dove Press journal: Neuropsychiatric Disease and Treatment

\author{
Pei-Lun Chung $\mathbb{D}^{\prime}$ \\ Chien-Wei Huang $\mathbb{D}^{2}$ \\ Min-Jing Lee $\mathbb{D}^{1,3}$ \\ Yao-Hsu Yang $\mathbb{1 D}^{4,5}$ \\ Ko-Jung Chen ${ }^{4}$ \\ Mong-Liang $\mathrm{Lu}^{6}$ \\ Jun-Cheng Weng ${ }^{1,7}$ \\ Vincent Chin-Hung Chen ${ }^{1,3}$ \\ 'Department of Psychiatry, Chang Gung \\ Memorial Hospital, Chiayi Branch, Chiayi, \\ Taiwan; ${ }^{2}$ Division of Nephrology, \\ Department of Medicine, School of \\ Medicine, Kaohsiung Veterans General \\ Hospital, and National Yang-Ming \\ University, Taiwan; ${ }^{3}$ School of Medicine, \\ Chang Gung University, Taoyuan, Taiwan; \\ ${ }^{4}$ Health Information and Epidemiology \\ Laboratory, Chang Gung Memorial \\ Hospital, Chiayi Branch, Chiayi, Taiwan; \\ ${ }^{5}$ Department of Traditional Chinese \\ Medicine, Chang Gung Memorial \\ Hospital, Chiayi Branch, Chiayi, Taiwan; \\ ${ }^{6}$ Department of Psychiatry, School of \\ Medicine, College of Medicine, Taipei \\ Medical University, Taipei, Taiwan; \\ ${ }^{7}$ Department of Medical Imaging and \\ Radiological Sciences, Chang Gung \\ University, Taoyuan, Taiwan
}

Purpose: This study explored and compared the effects of depression and antidepressants on sexual dysfunction in men with diabetes mellitus (DM).

Patients and Methods: Patients older than 18 years who had been newly diagnosed with DM (International Classification of Diseases, Ninth Revision, Clinical Modification [ICD9-CM] code 250) between 1999 and 2010 were identified from Taiwan's National Health Insurance Research Database and were followed up until 2013. Patients with preexisting depression or sexual dysfunction were excluded. A total of 636,210 patients with DM were enrolled. These patients were divided into two groups: DM with comorbid depression and a matched cohort without depression. The groups were followed up until the end of 2010 for the first diagnosis of sexual dysfunction (ICD-9-CM codes 302.70, 302.71, 302.72, 302.74, 302.75, 302.76, 302.79, 607.84, and V417). A Cox proportional hazard model and a Cox regression model with time-dependent covariates were applied.

Results: Patients with DM and depression had a higher risk of sexual dysfunction than those with $\mathrm{DM}$ without depression (hazard ratio $[\mathrm{HR}]=1.44 ; 95 \%$ confidence interval $[\mathrm{CI}], 1.33-1.55$ ). The risk of sexual dysfunction was lower in the subgroup who used antidepressants (per 28 cumulative defined daily doses [cDDDs]), $\mathrm{HR}=0.96 ; 95 \% \mathrm{CI}, 0.94-0.97$ ). A significantly lower incidence of sexual dysfunction was also associated with the use of selective serotonin reuptake inhibitors (SSRIs, per 28 cDDD). The adjusted HR was 0.95 (95\% CI, 0.93-0.97). Subgroup analysis indicated that SSRI use was significantly associated with an amelioration of erectile dysfunction (per 28 cDDD), with an HR of 0.95 (95\% CI, 0.92-0.97).

Conclusion: Male patients with DM and depression are at increased risk of sexual dysfunction. Antidepressant use had a small inverse association with the risk of sexual dysfunction in men with DM and depression. Antidepressants, in particular SSRIs, did not increase the risk of sexual dysfunction in this population.

Keywords: selective serotonin reuptake inhibitor, SSRI, sexual functioning, diabetes mellitus, depression

\section{Introduction}

Diabetes mellitus (DM) is a common chronic illness, and its incidence has rapidly increased over the past three decades ${ }^{1}$ In 2014, an estimated 422 million adults aged over 18 years had DM worldwide, ${ }^{2}$ and this number is estimated to increase to more than 500 million by $2018^{3}$ DM is also associated with a high comorbidity prevalence rate; one study reported that $97.5 \%$ of patients had at least one comorbidity and $88.5 \%$ had at least two ${ }^{4} \mathrm{DM}$ also commonly involves psychiatric morbidities, such as depression, and
Correspondence: Vincent Chin-Hung Chen

Department of Psychiatry, Chang Gung Memorial Hospital, Chiayi, Taiwan Email cch1966@gmail.com 
has a substantial impact on the quality of life. ${ }^{5,6}$ One metaanalysis indicated that patients with DM are twice as likely to have depression compared with those without it. ${ }^{7}$ Among all the comorbidities of DM, depression is a leading cause of disability and leads to high health-care costs. ${ }^{8}$

One meta-analysis of cross-sectional studies reported that patients with DM and depression exhibited poorer glycemic control and had a higher prevalence of multiple DM-related complications, including retinopathy, nephropathy, neuropathy, macrovascular complications, and sexual dysfunction. ${ }^{9}$ Another study revealed that severe depressive symptoms are associated with ejaculatory problems, hypoactive sexual desire, and hypogonadism in patients newly diagnosed with type II DM. ${ }^{10}$ Sexual dysfunction negatively affects men's quality of life. It impairs their sense of self-worth and competence and damages intimate relationships, hindering their recovery from depression. ${ }^{11,12}$ Detecting depression and treating it as early as possible are essential.

Sexual dysfunction is a side effect of most commonly prescribed antidepressants, which frequently results in treatment noncompliance in men. ${ }^{13}$ Antidepressants with serotonergic effects are more likely to cause sexual dysfunction than are those that act on the adrenergic or dopaminergic system. ${ }^{14}$ However, researchers investigating the use of antidepressants for treating patients with DM and depression have reported that selective serotonin reuptake inhibitors (SSRIs) have favorable effects on both depressive symptoms and glycemic control ${ }^{15}$ Antidepressants, in particular SSRIs, may have both positive and negative effects on patients with DM and depression. Thus, investigating the effects of antidepressants on sexual function among men with DM and depression is warranted.

After considering the sexual side effects of antidepressants, patients with DM and their physicians may hesitate to select them for treatment. No research has investigated the differences among antidepressant classes in terms of sexual function in patients with DM and comorbid depression ${ }^{15}$ Moreover, most studies have adopted crosssectional designs, which may underestimate the incidence rate of depression and DM complications, rather than longitudinal designs. In addition, the sample sizes of these studies are small. ${ }^{9,15}$ We conducted a populationbased cohort study by using a national database in Taiwan to explore how different classes of antidepressants affect sexual function in patients with DM and depressive disorder.

\section{Patients and Methods Data Source}

The National Health Insurance program, in operation since March 1995, covers $99.5 \%$ of the population of Taiwan. This study used the National Health Insurance Research Database (NHIRD), which contains information on insured patients, such as patient identification numbers, demographic data, dates of clinical visits, diagnostic codes according to the International Classification of Diseases, Ninth Revision, Clinical Modification (ICD9-CM), and prescriptions. The NHIRD does not contain any personally identifiable information. In this database, no statistically significant differences are observed in age, sex, or health-care costs among patients. ${ }^{16}$

\section{Study Population}

We identified all men aged 18 years or older who received a new diagnosis of DM (ICD-9-CM code 250) between January 1, 1999, and December 31, 2010, from the NHIRD $(\mathrm{N}=681,469)$. Patients diagnosed with depression (ICD-9-CM codes 296.2, 296.3, 300.4, and 311) prior to developing DM were excluded $(\mathrm{N}=31,920)$. Patients with any type of sexual dysfunction (ICD-9-CM codes 302.70 [psychosexual dysfunction, unspecified], 302.71 [psychosexual dysfunction with inhibited sexual desire], 302.72 [psychosexual dysfunction with inhibited sexual excitement], 302.74 [psychosexual dysfunction with inhibited male orgasm], 302.75 [psychosexual dysfunction with premature ejaculation], 302.76 [psychosexual dysfunction with functional dyspareunia], 302.79 [psychosexual dysfunction with other specified], 607.84 [impotence of organic origin], and V417 [problems with sexual function]) prior to diagnosis of $\mathrm{DM}(\mathrm{N}=12,088)$ and depression $(\mathrm{N}=1251)$ were also excluded. Ultimately, 636,210 patients diagnosed with DM between 1999 and 2010 were identified (see Figure 1 for the study flowchart).

We initiated follow-up on the date of the first diagnosis of depression for the group with DM and comorbid depression. The year of DM diagnosis, age, residential region, and income of this group were matched with a control group (1:4) comprising patients randomly selected from the same cohort. The date of depression diagnosis of a patient with DM and comorbid depression served as the index date for each matched control. We enrolled patients of sexual dysfunction with the aforementioned diagnosis codes who had visited the outpatient department at least twice in 1 year or had been admitted 


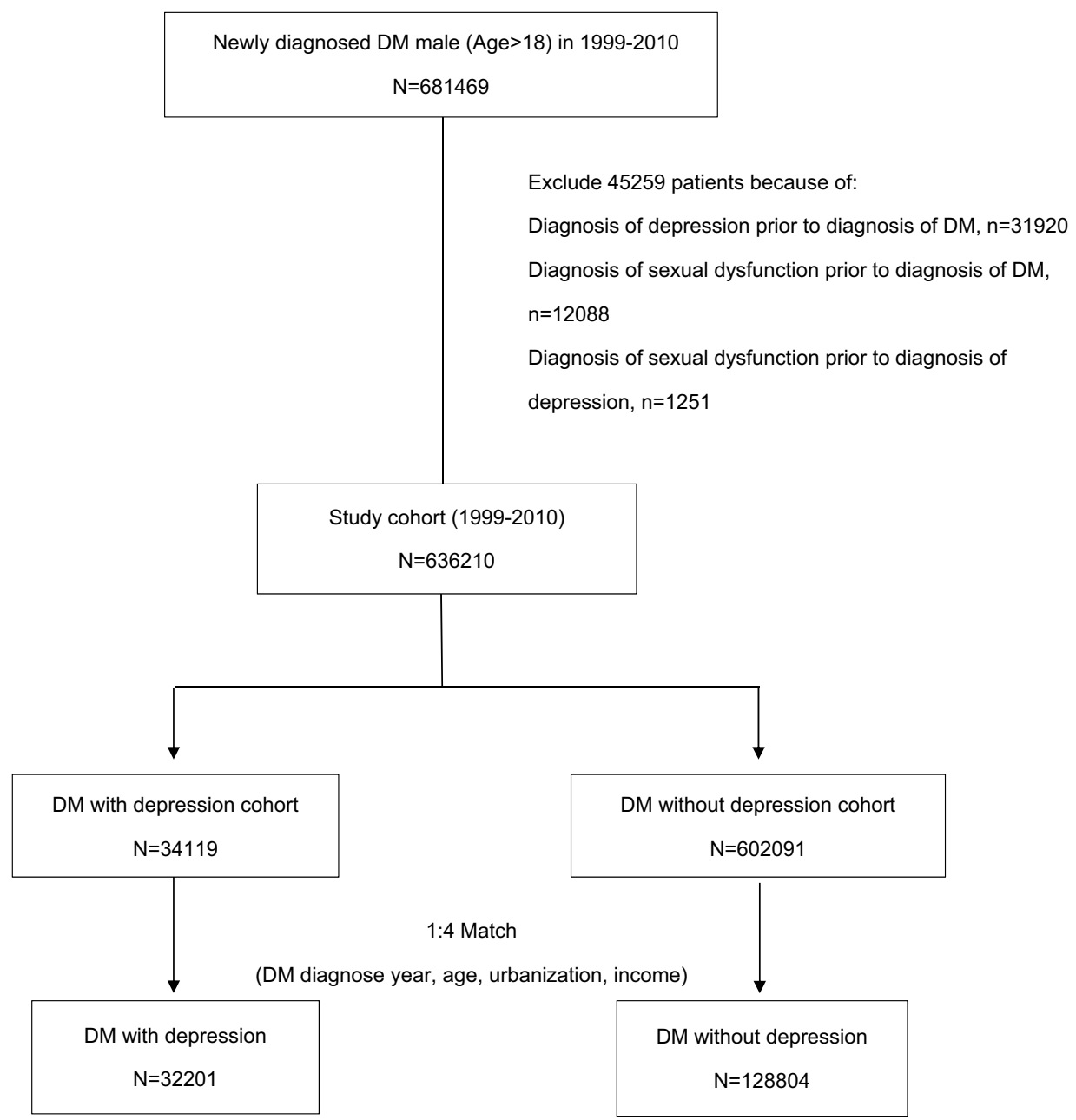

Figure I Study design flowchart.

to medical care institutions at least once a year between 1999 and 2010. The endpoint of the study was defined as the date of diagnosis of sexual dysfunction (ICD-9-CM codes 302.70, 302.71, 302.72, 302.74, 302.75, 302.76, 302.79, 607.84, and V417), death, or the end of 2013.

The Chiayi Chang Gung Memorial Hospital Institutional Review Board approved this study.

\section{Statistical Analysis}

The distribution of demographic characteristics and proportions of comorbidities were compared between the group with DM and comorbid depression and the control group. We also included adapted Diabetes Complication Severity Index scores for each patient ${ }^{17}$ (Table 1). We analyzed the individual effect of depression and antidepressant dosage (cumulative defined daily dose [cDDD]) ${ }^{18}$ on sexual dysfunction, with adjustments for age, residential region, income, comorbidities, and severity of DM. The following seven classes of antidepressants were analyzed: SSRI, serotonin-norepinephrine reuptake inhibitor, norepinephrine/ dopamine reuptake inhibitor, mirtazapine, serotonin antagonist and reuptake inhibitor, tricyclic/tetracyclic antidepressants, and reversible inhibitor of monoamine oxidase A, with adjustments for other covariates. A Cox proportional hazard model was used to determine hazard ratios (HRs) and 95\% confidence intervals (CIs) for examining the effect of depression on sexual dysfunction after adjustment for sex, age, urbanization level, income, and comorbidities. A Cox regression model with time-dependent covariates was performed to evaluate the effects of the different antidepressant classes on sexual dysfunction. Time-dependent analysis is recommended for observational studies of survival outcomes to minimize the risk of immortal time bias ${ }^{19}$ Twotailed $\mathrm{P}$ value of 0.05 was considered significant. Analyses were conducted using SAS version 9.4 (SAS Institute, Cary, $\mathrm{NC}, \mathrm{USA}$ ). 
Table I Characteristics of DM Patients with and Without Depression

\begin{tabular}{|c|c|c|c|c|c|}
\hline \multirow[t]{2}{*}{ Variables } & \multicolumn{2}{|c|}{$\begin{array}{l}\text { DM with } \\
\text { Depression } \\
(\mathrm{N}=32,201)\end{array}$} & \multicolumn{2}{|c|}{$\begin{array}{l}\text { DM Without } \\
\text { Depression } \\
(\mathrm{N}=\mid \mathbf{2 8 , 8 0 4})\end{array}$} & \multirow[t]{2}{*}{$P$ value } \\
\hline & $\mathbf{n}$ & $\%$ & $\mathbf{n}$ & $\%$ & \\
\hline Age (year) & & & & & 1.0000 \\
\hline $19-64$ & 19,297 & 59.93 & 77,188 & 59.93 & \\
\hline$\geq 65$ & 12,904 & 40.07 & 51,616 & 40.07 & \\
\hline Urbanization level & & & & & 1.0000 \\
\hline I (City) & 8900 & 27.64 & 35,600 & 27.64 & \\
\hline 2 & 15,298 & 47.51 & 61,192 & 47.51 & \\
\hline 3 & 5412 & 16.81 & 21,648 & 16.81 & \\
\hline 4 (Villages) & 2591 & 8.05 & 10,364 & 8.05 & \\
\hline Income & & & & & 1.0000 \\
\hline 0 & 3279 & 10.18 & 13,116 & 10.18 & \\
\hline$I-15,840$ & 7101 & 22.05 & 28,404 & 22.05 & \\
\hline$|5,84|-25,000$ & 13,479 & 41.86 & 53,916 & 41.86 & \\
\hline$>25,000$ & 8342 & 25.91 & 33,368 & 25.91 & \\
\hline Sexual dysfunction & & & & & $<0.0001$ \\
\hline Yes & 1068 & 3.32 & 3192 & 2.48 & \\
\hline No & 31,133 & 96.68 & $125,6 \mid 2$ & 97.52 & \\
\hline Death & & & & & $<0.0001$ \\
\hline Yes & 6064 & 18.83 & 18,163 & 14.10 & \\
\hline No & 26,137 & 81.17 & $|10,64|$ & 85.90 & \\
\hline $\begin{array}{l}\text { Adapted diabetes } \\
\text { complication } \\
\text { severity index } \\
(\text { Mean } \pm \text { SD) }\end{array}$ & \multicolumn{2}{|c|}{$0.59 \pm 1.01$} & \multicolumn{2}{|c|}{$0.47 \pm 0.93$} & $<0.0001$ \\
\hline
\end{tabular}

\section{Results}

(Table 1) presents the demographic characteristics of male patients with DM and comorbid depression and the control group. Age, residential region, and income level did not statistically differ between the two groups. Overall, a significantly higher incidence of sexual dysfunction was observed among male patients with DM and comorbid depression than that in the control group $(\mathrm{HR}=1.44 ; 95 \%$ CI, 1.33-1.55, $\mathrm{P}<0.0001$; Table 2). The percentage of patients diagnosed with dysfunction of libido (ICD-9-CM code 302.71), erection (ICD-9-CM codes 302.72 and 607.84), ejaculation (ICD-9-CM codes 302.74 and 302.75), or other causes (ICD-9-CM codes 302.70, 302,76, 302.79, and V41.7) was $0.06 \%(\mathrm{~N}=19), 2.72 \%(\mathrm{~N}=875), 0.07 \%$ $(\mathrm{N}=0.07)$, and $0.50 \%(\mathrm{~N}=160)$, respectively (Table 3$)$. The cumulative incidence of sexual dysfunction in male patients with DM and comorbid depression and the control group is listed in (Figure 2). Per 100,000 person-years, the incidence rate of sexual dysfunction was 647.3 (95\% CI, 609.7-687.4) in male patients with DM and comorbid depression and 471.2 (95\% CI, 455.1-487.8) in controls. The median follow-up time was 5.1 years for the DM with comorbid depression group and 5.3 years for the control group.

A significantly lower risk of sexual dysfunction was noted in patients with DM and depression who used antidepressants (per 28 cDDD; HR $=0.96$; 95\% CI, 0.94-0.97; $\mathrm{P}<0.0001$; Table 4).

The associations between type of antidepressant and incidence of sexual dysfunction in the DM with comorbid depression group are listed in (Table 5). A significantly lower incidence rate of sexual dysfunction was discovered, particularly among those using SSRIs (per 28 cDDD; HR $=0.95 ; 95 \%$ CI, 0.93-0.97, P < 0.0001).

Further analysis of how SSRIs affect various types of sexual dysfunction is presented in (Table 6). Patients with DM and depression who used SSRIs exhibited a significantly lower risk of erectile dysfunction (per 28 cDDD; HR =0.95; 95\% CI, 0.92-0.97; P <0.0001).

\section{Discussion}

To the best of our knowledge, this is the first study to use a national database to explore the overall and individual effects of antidepressants on sexual function in male patients with DM and comorbid depression. We discovered that their

Table 2 Cox Regression Analysis of Sexual Dysfunction in Patients with DM

\begin{tabular}{|c|c|c|c|c|c|c|c|c|}
\hline \multirow{3}{*}{$\begin{array}{l}\text { Variables } \\
\text { Depression }\end{array}$} & \multicolumn{4}{|c|}{ Crude } & \multicolumn{4}{|c|}{ Adjusted $^{\mathrm{a}}$} \\
\hline & \multirow[t]{2}{*}{ HR } & \multicolumn{2}{|c|}{$95 \% \mathrm{Cl}$} & \multirow[t]{2}{*}{ P value } & \multirow[t]{2}{*}{ HR } & \multicolumn{2}{|c|}{$95 \% \mathrm{Cl}$} & \multirow[t]{2}{*}{$P$ value } \\
\hline & & & & & & & & \\
\hline Yes & 1.37 & 1.28 & 1.47 & $<0.0001$ & 1.44 & 1.33 & 1.55 & $<0.0001$ \\
\hline No & 1.00 & \multicolumn{2}{|c|}{ Reference } & & 1.00 & \multicolumn{2}{|c|}{ Reference } & \\
\hline
\end{tabular}

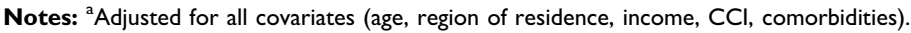

Abbreviation: $\mathrm{CCl}$, Charlson Comorbidity Index. 
Table 3 Analysis of the Percentage of Sexual Dysfunction Subgroup

\begin{tabular}{|l|l|l|}
\hline \multirow{2}{*}{ Variables } & \multicolumn{2}{|l|}{ DM with Depression (N=32,201) } \\
\cline { 2 - 3 } & $\mathbf{n}$ & $\%$ \\
\hline Sexual Dysfunction & \multicolumn{2}{|l}{} \\
\hline Libido & 19 & 0.06 \\
Erection & 875 & 2.72 \\
Ejaculation & 24 & 0.07 \\
Others & 160 & 0.50 \\
\hline
\end{tabular}

Notes: Dysfunction of libido: ICD-9-CM codes 302.71; dysfunction of the erection ICD-9-CM codes 302.72 and 607.84, dysfunction of ejaculation:ICD-9-CM codes 302.74 and 302.75, and dysfunction of other causes: ICD-9-CM codes $302.70,302.76,302.79$, and $\mathrm{V} 41.7$

incidence of sexual dysfunction was significantly higher than that in those without depression and that the use of antidepressants was associated with a lower risk of sexual dysfunction in these patients. Subgroup analysis revealed that SSRI usage was inversely associated with sexual dysfunction in men with DM and depression. Particularly, among the sexual dysfunction types under consideration, erectile dysfunction was significantly ameliorated by SSRI usage.

In this study, the use of antidepressants was linked to a lower risk of sexual dysfunction in patients with DM and comorbid depression, and in particular, SSRIs played a large role. Most research has reported that antidepressants cause sexual dysfunction in patients with depression; one meta-analysis revealed a prevalence of sexual dysfunction ranging from $25.8 \%$ to $80.3 \%$ in these patients. ${ }^{20}$ Each type of antidepressant has unique effects on neurotransmitters; these effects play a substantial role in their adverse effects on sexual function. Theoretically, antidepressants with serotonergic effects have more side

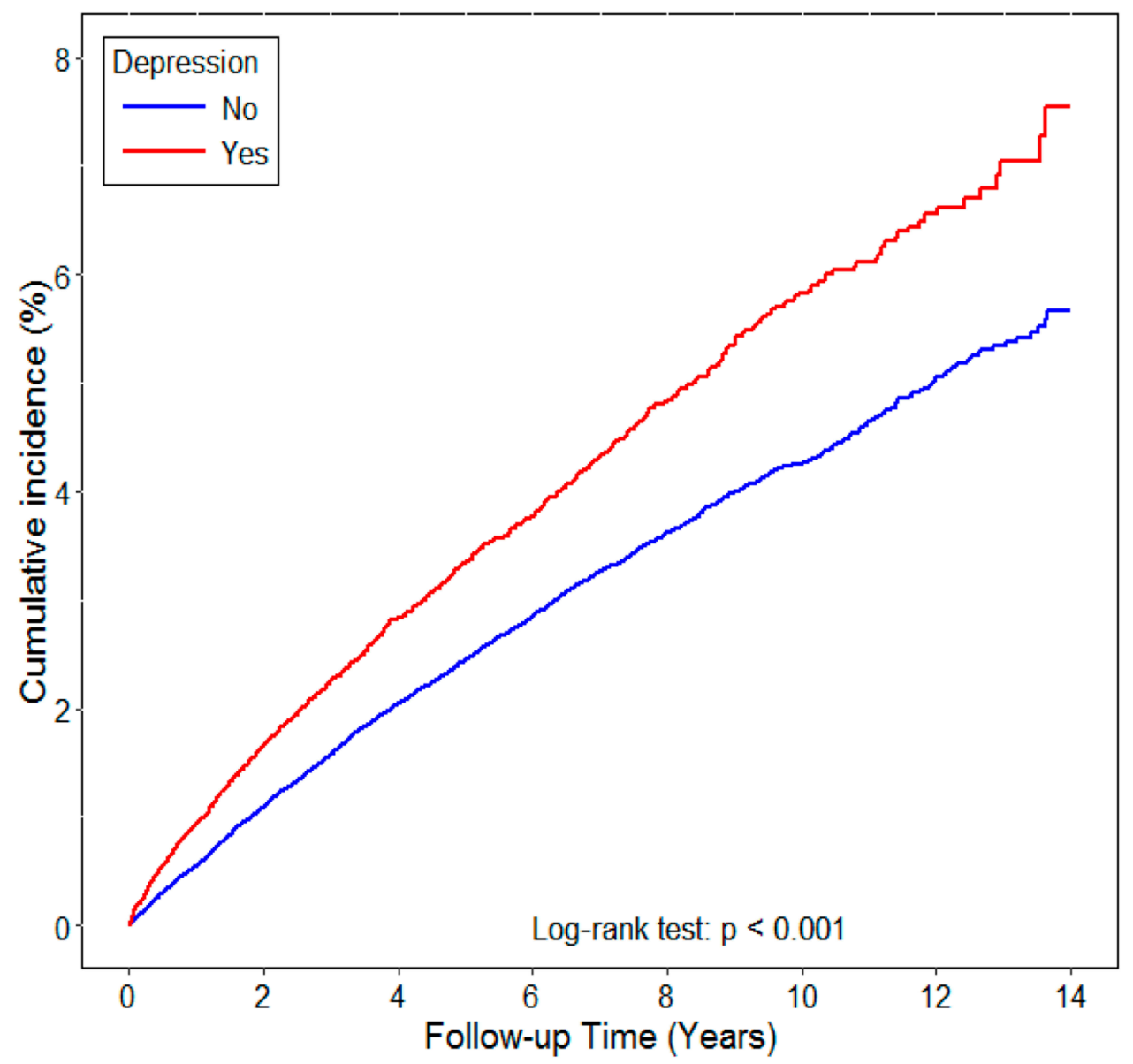

Number at risk

$\begin{array}{rrrrrrrrr}\text { No } & 128804 & 100657 & 73282 & 49943 & 30845 & 15500 & 5746 & 696 \\ \text { Yes } & 32201 & 24373 & 17580 & 12051 & 7566 & 3894 & 1494 & 186\end{array}$

Figure 2 Cumulative incidence of sexual dysfunction in male patients with DM and comorbid depression. 
Table 4 Time-Dependent Cox Regression Analysis of Sexual Dysfunction in Patients with DM and Comorbid Depression Treated with Antidepressants

\begin{tabular}{|l|l|l|l|l|l|l|l|l|}
\hline Variables & \multicolumn{4}{l|}{ Crude } & \multicolumn{4}{l|}{ Adjusted $^{\text {a }}$} \\
\cline { 2 - 10 } & HR & $\mathbf{9 5 \%} \mathbf{~ C l}$ & P value & HR & $\mathbf{9 5 \%} \mathbf{~ C l}$ & P value \\
\hline Antidepressants (per 28 cDDD) & 0.97 & 0.95 & 0.98 & $<0.0001$ & 0.96 & 0.94 & 0.97 & $<0.0001$ \\
\hline
\end{tabular}

Notes: aAjusted for all covariates (age, region of residence, income, aDCSI, comorbidities).

Abbreviation: aDCSI, adapted Diabetes Complications Severity Index.

Table 5 Time-Dependent Cox Regression Analysis of Sexual Dysfunction in Patients with DM and Comorbid Depression: Antidepressant Subgroup Analysis

\begin{tabular}{|c|c|c|c|c|c|c|c|c|}
\hline \multirow{3}{*}{$\begin{array}{l}\text { Variables } \\
\text { SSRI (per } 28 \text { cDDD) }\end{array}$} & \multicolumn{4}{|c|}{ Crude } & \multicolumn{4}{|c|}{ Adjusted $^{\mathrm{a}}$} \\
\hline & \multirow{2}{*}{$\begin{array}{l}\mathbf{H R} \\
0.96\end{array}$} & \multicolumn{2}{|c|}{$95 \% \mathrm{Cl}$} & \multirow{2}{*}{$\begin{array}{l}\text { P value } \\
<0.0001\end{array}$} & \multirow{2}{*}{$\begin{array}{l}\text { HR } \\
0.95\end{array}$} & \multicolumn{2}{|c|}{$95 \% \mathrm{Cl}$} & \multirow{2}{*}{$\begin{array}{l}P \text { value } \\
<0.0001\end{array}$} \\
\hline & & 0.93 & 0.98 & & & 0.93 & 0.97 & \\
\hline SNRI (per 28 cDDD) & 0.99 & 0.95 & 1.03 & 0.5653 & 0.96 & 0.94 & 1.01 & 0.2080 \\
\hline NDRI (per 28 cDDD) & 1.01 & 0.92 & 1.11 & 0.8409 & 0.99 & 0.90 & 1.09 & 0.7686 \\
\hline Mirtazapine (per 28 cDDD) & 0.99 & 0.95 & 1.02 & 0.4385 & 0.98 & 0.94 & 1.02 & 0.2728 \\
\hline TCA/tetracyclic ATD (per 28 cDDD) & 0.92 & 0.83 & 1.02 & 0.0961 & 0.93 & 0.84 & 1.03 & 0.1533 \\
\hline SARI (trazodone) (per 28 cDDD) & 0.94 & 0.86 & 1.04 & 0.2193 & 0.93 & 0.85 & 1.03 & 0.1508 \\
\hline RIMA (per 28 cDDD) & 0.96 & 0.86 & 1.07 & 0.4232 & 0.97 & 0.86 & 1.08 & 0.5189 \\
\hline
\end{tabular}

Notes: ${ }^{a}$ Adjustment for seven types of ATDs, age, region of residence, income, comorbidities, adapted Diabetes Complications Severity Index score.

Abbreviations: SSRI, selective serotonin reuptake inhibitors; SNRI, serotonin/norepinephrine reuptake inhibitors; NDRI, norepinephrine-dopamine reuptake inhibitors; ATD, antidepressant; SARI, serotonin antagonist and reuptake inhibitor; RIMA, reversible inhibitor of monoamine oxidase A.

Table 6 Time-Dependent Cox Regression Analysis of SSRI Effect on Patients with DM and Comorbid Depression: Sexual Dysfunction Subgroup Analysis

\begin{tabular}{|c|c|c|c|c|c|c|c|c|}
\hline \multirow{3}{*}{$\begin{array}{l}\text { Variables } \\
\text { Outcome: Libido } \\
\text { SSRI (per } 28 \text { cDDD) }\end{array}$} & \multicolumn{4}{|c|}{ Crude } & \multicolumn{4}{|c|}{ Adjusted $^{\mathrm{a}}$} \\
\hline & \multirow{2}{*}{$\begin{array}{l}\text { HR } \\
0.92\end{array}$} & \multicolumn{2}{|c|}{$95 \% \mathrm{Cl}$} & \multirow{2}{*}{$\begin{array}{l}\mathbf{P} \text { value } \\
0.3789\end{array}$} & HR & \multicolumn{2}{|c|}{$95 \% \mathrm{Cl}$} & $P$ value \\
\hline & & 0.77 & 1.10 & & \multicolumn{4}{|l|}{$N A^{b}$} \\
\hline $\begin{array}{l}\text { Outcome: Erection } \\
\text { SSRI (per } 28 \text { cDDD) }\end{array}$ & 0.94 & 0.92 & 0.97 & $<0.0001$ & 0.95 & 0.92 & 0.97 & $<0.0001$ \\
\hline $\begin{array}{l}\text { Outcome: Ejaculation } \\
\text { SSRI (per } 28 \text { cDDD) }\end{array}$ & 0.93 & 0.82 & 1.07 & 0.3259 & $N A^{b}$ & & & \\
\hline
\end{tabular}

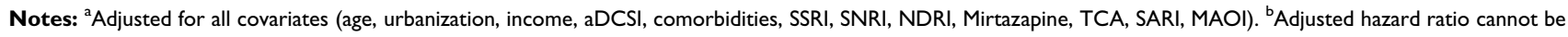
analyzed due to the small sample size. Dysfunction of libido: ICD-9-CM codes 302.7I; dysfunction of the erection:ICD-9-CM codes 302.72 and 607.84, dysfunction of ejaculation: ICD-9-CM codes 302.74 and 302.75, and dysfunction of other causes: ICD-9-CM codes 302.70, 302.76, 302.79, and V4I.7.

Abbreviations: aDCSI, adapted Diabetes Complications Severity Index; SSRI, selective serotonin reuptake inhibitors; SNRI, serotonin/norepinephrine reuptake inhibitors; NDRI, norepinephrine-dopamine reuptake inhibitors; TCA, tetracyclic antidepressant; SARI, serotonin antagonist and reuptake inhibitor; RIMA, reversible inhibitor of monoamine oxidase $A$.

effects on sexual function than those that act on the adrenergic or dopaminergic system. ${ }^{13}$ Nevertheless, SSRIs are typically the first choice for depression treatment. ${ }^{21}$ Recent studies have also recommended the use of SSRIs in men with depression and DM. One systemic review indicated that SSRIs improve glycemic control, leading to lower HbA1c levels, improved depression control, and prolongation of the depression-free interval in men who have DM with comorbid depression. ${ }^{15}$ By contrast, tricyclic antidepressants might reduce glucose tolerance and worsen glucose control. ${ }^{15}$ Other antidepressants such as bupropion and agomelatine appear to favorably affect glucose control, but this observation requires further investigation. $^{15}$ Other studies have suggested using 
SSRIs to treat patients with DM and depression because these medications reduce fasting and postmeal blood sugar levels, ${ }^{22}$ improve prophylaxis against depression recurrence, and reduce $\mathrm{HbA} 1 \mathrm{c}$ levels. ${ }^{23}$ Our findings suggest that SSRIs are effective in treating patients with DM and comorbid depression and limit the concern of sexual dysfunction in this specific population. However, the effect size was comparable for all types of antidepressants, and the significant effect only for SSRIs may be the result of a larger sample size.

The discrepancy in the results might be related to the unique population of our study. One possible explanation might be indication bias; that is, without the sexual dysfunction complication, the dosage of serotonergic agents such as SSRIs may be increased or they may be replaced with another antidepressant agent. Another study indicated that when depressive symptoms improved in patients who had DM with comorbid depression, glycemic control also improved $^{24}$ Cross-sectional studies have also reported associations between improved glycemic control and ameliorated sexual dysfunction in men with DM. ${ }^{25,26} \mathrm{DM}$ itself may affect sexual function through multiple pathophysiological pathways and have vascular, neurological, and hormonal effects. ${ }^{27-30}$ Basic end-organ damage caused by hyperglycemia may result in sexual dysfunction, particularly erectile dysfunction. ${ }^{26}$ Another possible explanation may be the lower hypercoagulation state associated with SSRI use. ${ }^{31}$ Complex vascular and neural interactions cause the relaxation of the cavernosal smooth muscle, which controls penile erection. ${ }^{32,33}$ One prospective randomized controlled study indicated that antiplatelet therapy (in the form of aspirin) significantly ameliorated erectile dysfunction by inhibiting platelet activity ${ }^{34}$ SSRIs play a similar role in reducing platelet activity and may improve erectile function. ${ }^{35}$

The findings of the present study on the association between depression and the potential increased risk of sexual dysfunction in men with DM are consistent with those of other studies. ${ }^{9,10}$ All of the studies available for analysis have small subgroups and have adopted a crosssectional design rather than a prospective longitudinal approach with meta-analytic procedures. ${ }^{9}$

\section{Strengths and Limitations}

We used a cohort design and a population-based database to overcome selection bias. Other studies have diagnosed sexual dysfunction based on self-evaluation. ${ }^{10}$ We used physician diagnoses, which are more reliable than self- evaluations of comorbidities. ${ }^{36}$ SSRIs were included as a time-dependent variable to minimize the risk of immortal time bias. However, this study has limitations. Data were retrieved from the NHIRD, which contains information only from visits to public hospitals and clinics. Because of privacy concerns and local cultural norms, patients may have sought private treatment for sexual problems, potentially causing selection bias and an underestimation of sexual dysfunction incidence. The NHIRD does not document physical examination results, such as the varicocele or the volume of the testis and sex hormone levels. Thus, we were unable to evaluate the influence of these factors. Some personal information related to glycemic control, such as hemoglobin A1c, fasting plasma glucose, and postmeal blood sugar levels, is not available from the NHIRD. Additional studies using more detailed data on glycemic control in patients with sexual dysfunction that improved after antidepressant treatment are warranted. Finally, the study sample was identified from the Taiwanese population; hence, the study findings should not be generalized to other populations.

\section{Conclusion}

The findings of this large-scale nationwide claims-based study indicate that male patients with DM and comorbid depression have a higher risk of sexual dysfunction. Our findings suggest that antidepressant use is linked to a lower risk of sexual dysfunction. Studies in other populations are warranted.

\section{Disclosure}

The authors report no conflicts of interest in this work.

\section{References}

1. Chen L, Magliano DJ, Zimmet PZ. The worldwide epidemiology of type 2 diabetes mellitus - present and future perspectives. Nat Rev Endocrinol. 2011;8(4):228. doi:10.1038/nrendo.2011.183

2. Zhou B, Lu Y, Hajifathalian K, Worldwide trends in diabetes since. Worldwide trends in diabetes since 1980: a pooled analysis of 751 population-based studies with 44 million participants. Lancet 2016;387(10027):1513-1530. doi:10.1016/S0140-6736(16)00618-8.

3. Kaiser AB, Zhang N, Der Pluijm WV. Global Prevalence of Type 2 Diabetes over the Next Ten Years (2018-2028). Diabetes. 2018;67 (Supplement 1):202-LB. doi:10.2337/db18-202-LB

4. Iglay K, Hannachi H, Joseph Howie P, et al. Prevalence and co-prevalence of comorbidities among patients with type 2 diabetes mellitus. Curr Med Res Opin. 2016;32(7):1243-1252. doi:10.1185/ 03007995.2016.1168291

5. Brown GC, Brown MM, Sharma S, Brown H, Gozum M, Denton P. Quality of life associated with diabetes mellitus in an adult population. J Diab Comp. 2000;14(1):18-24. doi:10.1016/S1056-8727(00)00061-1 
6. Verma SK, Luo N, Subramaniam M, et al. Impact of depression on health related quality of life in patients with diabetes. Ann Acad Med Singapore. 2010;39(12):913-917.

7. Anderson RJ, Freedland KE, Clouse RE, Lustman PJ. The prevalence of comorbid depression in adults with diabetes: a meta-analysis. Diabetes Care. 2001;24(6):1069. doi:10.2337/diacare.24.6.1069

8. Katon WJ. The comorbidity of diabetes mellitus and depression. Am $J$ Med. 2008;121(Suppl 11):S8-15. doi:10.1016/j.amjmed.2008. 09.008

9. de Groot M, Anderson R, Freedland KE, Clouse RE, Lustman PJ. Association of depression and diabetes complications: a meta-analysis. Psychosom Med. 2001;63(4):619-630. doi:10.1097/ 00006842-200107000-00015

10. Corona G, Giorda CB, Cucinotta D, Guida P, Nada E. Sexual dysfunction at the onset of type 2 diabetes: the interplay of depression, hormonal and cardiovascular factors. $J$ Sex Med. 2014;11 (8):2065-2073. doi:10.1111/jsm.12601

11. Labbate LA. Psychotropics and sexual dysfunction: the evidence and treatments. Adv Psychosom Med. 2008;29:107-130.

12. De Berardis G, Franciosi M, Belfiglio M, et al. Erectile dysfunction and quality of life in type 2 diabetic patients: a serious problem too often overlooked. Diabetes Care. 2002;25(2):284-291. doi:10.2337/ diacare.25.2.284

13. Segraves RT, Balon R. Antidepressant-induced sexual dysfunction in men. Pharmacol Biochem Behav. 2014;121:132-137. doi:10.1016/j. pbb.2013.11.003

14. Clayton AH, Croft HA, Handiwala L. Antidepressants and sexual dysfunction: mechanisms and clinical implications. Postgrad Med. 2014;126(2):91-99. doi:10.3810/pgm.2014.03.2744

15. Roopan S, Larsen ER. Use of antidepressants in patients with depression and comorbid diabetes mellitus: a systematic review. Acta Neuropsychiatr. 2017;29(3):127-139. doi:10.1017/neu.2016.54

16. Wu T-Y, Majeed A, Kuo KN. An overview of the healthcare system in Taiwan. London J Prim Care. 2010;3(2):115-119. doi:10.1080/ 17571472.2010.11493315

17. Young BA, Lin E, Von Korff M, et al. Diabetes complications severity index and risk of mortality, hospitalization, and healthcare utilization. Am J Manag Care. 2008;14(1):15-23.

18. Wertheimer AI. The defined daily dose system (DDD) for drug utilization review. Hosp Pharm. 1986;21(3):233-234, 239-241, 258.

19. Jones M, Fowler R. Immortal time bias in observational studies of time-to-event outcomes. J Crit Care. 2016;36:195-199. doi:10.1016/ j.jcrc.2016.07.017

20. Serretti A, Chiesa A. Treatment-emergent sexual dysfunction related to antidepressants: a meta-analysis. J Clin Psychopharmacol. 2009;29(3):259-266. doi:10.1097/JCP.0b013e3181a5233f

21. Gautam S, Jain A, Gautam M, Vahia VN, Grover S. Clinical practice guidelines for the management of depression. Indian J Psychiatry. 2017;59(Suppl 5):S34-S50. doi:10.4103/0019-5545.196973
22. Dhavale HS, Panikkar V, Jadhav BS, Ghulghule M, Dagaria A. Depression and diabetes: impact of anti-depressant medications on glycaemic control. J Ass Phy India. 2013;61(12):896-899.

23. Lustman PJ, Clouse RE, Nix BD, et al. Sertraline for prevention of depression recurrence in diabetes mellitus: a randomized, double-blind, placebo-controlled trial. Arch Gen Psychiatry. 2006;63(5):521-529. doi:10.1001/archpsyc.63.5.521

24. Radojkovic J, Sikanic N, Bukumiric Z, Tadic M, Kostic N, Babic R. Improvement of glycemic control in insulin-dependent diabetics with depression by concomitant treatment with antidepressants. Med sci mon. 2016;22:2133-2143. doi:10.12659/MSM.899571

25. Roth A, Kalter-Leibovici O, Kerbis Y, et al. Prevalence and risk factors for erectile dysfunction in men with diabetes, hypertension, or both diseases: a community survey among 1412 Israeli men. Clin Cardiol. 2003;26(1):25-30. doi:10.1002/clc.4960260106

26. Romeo JH, Seftel AD, Madhun ZT, Aron DC. Sexual function in men with diabetes type 2: association with glycemic control. J Urol. 2000;163(3):788-791. doi:10.1016/S0022-5347(05)67805-6

27. Kim NN. Sex steroid hormones in diabetes-induced sexual dysfunction: focus on the female gender. $J$ Sex Med. 2009;6(Suppl 3):239-246. doi:10.1111/j.1743-6109.2008.01182.x

28. Morano S. Pathophysiology of diabetic sexual dysfunction. $J$ Endocrinol Invest. 2003;26(3 Suppl):65-69.

29. Kaiser FE, Korenman SG. Impotence in diabetic men. Am J Med. 1988;85(5):147-152. doi:10.1016/0002-9343(88)90408-1

30. McCulloch DK, Young RJ, Prescott RJ, Campbell IW, Clarke BF. The natural history of impotence in diabetic men. Diabetologia. 1984;26(6):437-440. doi:10.1007/BF00262216

31. Sauer WH, Berlin JA, Kimmel SE. Effect of antidepressants and their relative affinity for the serotonin transporter on the risk of myocardial infarction. Circulation. 2003;108(1):32-36. doi:10.1161/01. CIR.0000079172.43229.CD

32. Toda N, Ayajiki K, Okamura T. Nitric oxide and penile erectile function. Pharmacol Ther. 2005;106(2):233-266. doi:10.1016/j. pharmthera.2004.11.011

33. Hafez G, Gonulalan U, Kosan M, et al. Acetylsalicylic acid protects erectile function in diabetic rats. Andrologia. 2014;46(9):997-1003. doi:10.1111/and.12187

34. Bayraktar Z, Albayrak S. Antiplatelet(aspirin) therapy as a new option in the treatment of vasculogenic erectile dysfunction: a prospective randomized double-blind placebo-controlled study. Int Urol Nephrol. 2018;50(3):411-418. doi:10.1007/s11255-0181786-0

35. Maurer-Spurej E. Serotonin reuptake inhibitors and cardiovascular diseases: a platelet connection. Cell Mol Life Sci. 2005;62 (2):159-170. doi:10.1007/s00018-004-4262-1

36. Taiwan NHIRD. Specific data subsets in NHIRD. Available from: https://nhird.nhri.org.tw/en/Data_Subsets.html.
Neuropsychiatric Disease and Treatment

\section{Publish your work in this journal}

Neuropsychiatric Disease and Treatment is an international, peerreviewed journal of clinical therapeutics and pharmacology focusing on concise rapid reporting of clinical or pre-clinical studies on a range of neuropsychiatric and neurological disorders. This journal is indexed on PubMed Central, the 'PsycINFO' database and CAS, and is the official journal of The International Neuropsychiatric Association (INA). The manuscript management system is completely online and includes a very quick and fair peer-review system which is all easy to use. Visit http://www.dovepress.com/testimonials.php to read real quotes from published authors. 